\title{
Middlemen Market Power and Land Reform Policy Implication: An Imperfect Competition Analysis for the Traditional Food Market of Vietnam
}

\author{
Ngo Chi Thanh ${ }^{1}$ \\ ${ }^{1}$ Lecturer of Faculty of Economics and Business Administration, Department of Science and Technology \\ Mangement, Hong Duc University, Vietnam \\ Correspondence: Ngo Chi Thanh, Department of Science and Technology Mangement, Hong Duc University, No \\ 565 Quang Trung Street, Dong Ve Ward, Thanh Hoa city, Vietnam. E-mail: ngochithanh@ @ hdu.edu.vn
}

Received: February 10, 2018

Accepted: March 5, 2018

Online Published: March 25, 2018

doi:10.5539/ijef.v10n5p31

URL: https://doi.org/10.5539/ijef.v10n5p31

\begin{abstract}
The traditional food distribution system is often characterized by small farmers and of several retailer called middlemen who sell their products on market. Since the intermediaries and their market powers are largely considerable in the food market, this paper proposes an industrial organization model of the middlemen in this conventional food distribution system for developing countries. Since most of the works in this field has adopted an empirical approach, the focus of our study in this paper will be instead on theoretical model. In order to analyze this situation, we borrow several arguments from the theory of imperfect competition. We assume that middlemen have oliopsony and oligopoly power in the up and down stream of the food system. We defined the consumer behavior by discrete choice model and study the quantity flow from small producers to the consumers by mean of Cournot competition. We address the question of land reform policy implication by creating a productivity shock in order to examine the effect of this instrument on the wealth of both farmers and consumers.
\end{abstract}

Keywords: traditional food distribution, imperfect competition, middlemen, market power, Vietnam economics

\section{Introduction}

The traditional retail system accounts for the majority of delivering agricultural products in developing countries. For instance, it is nearly $90 \%$ of the food production distributed by this channel in the domestic market in the case of Vietnam. This conventional system is described as having basic but poor conditions and selling products without really taking care of the quality of the products (Maruyama \& Trung 2007, 2010, 2012); The channel has however some features: (i) the flow of foods basically moves from the farmers to the consumers through several collectors called the middlemen; (ii) In the supply side of the food market, there is a large number of farmers, who just exploit in a small part of land and live at commune level (see Moustier et al., 2007; Hung et al., 2007; and GSO 2017a,b), while in the intermediary, there are not too many middlemen who transport foods to the cities to sell at competitive markets. Based on such consideration, market power of middlemen may have an effect on the wealth of farmers. From that point of view, the objective of this paper is to study the market power of middlemen in the conventional food system.

Focusing on the intermediaries and their market power in agricultural markets, since 1922, Nourse had the earliest works discussing the imbalance in market power between farmers and marketing firm buying products from farmers. Several papers of Sexton Lavoie (2001), McCorriston (2002), Rogers and Sexton (1994), and Myers, Sexton, and Tomek (2010) emphasize that market power is paying more attention in to the agricultural market; Chau, Goto, and Kanbur (2007) build the model of middlemen by using the Bertrand Benchmark competition. Merel, Sexton, and Suzuky (2009) argue that high transport cost can be an important reason which can lead to middlemen's market power. The focus of our study in this paper will be on theoretically modeling the market power of middlemen in the conventional food distribution system in particularly for the context of Vietnam.

For the case of Vietnam, there are several studies on middlemen behavior in the traditional food distribution sysytem. For instance, Wijk et al. (2006) describes the vegetable producers, the traders, and the location of buying these products. Wiersinga (2004) observes that collectors go around of farm fields, negotiate the price, 
then transport and sell fruits and vegetables to the markets. P. Moustier et al. (2007) emphasize that middlemen are responsible for collecting foods from different locations. In this way, they have oliopsony and oligopoly power in the up and down stream of the food distribution system. We observerd that, most of the works studying on middlemen beahavior by different approaches but not using the tool of imperfect competition. This is the reason why we propose a theoretical model of middlemen market power in both sides of the food market by an imperfect competition approach.

Since the intermediaries and their market powers are largely considerable in the food market (see Sexton \& Lavoie, 2001; McCorriston, 2002; and Myers et al., 2010). The strategy of this paper is to borrow several arguments based on the theory of the imperfect competition. We assume that the middlemen have market power in both upstream and downstream of the traditional food distribution system. This is typically the case of Vietnam where middlemen buy foods from farmers, then transports and sells it to the consumer markets. Small farmers are characterized by a production function, and the consumer's behaviors is defined by a discrete choice model. The inverse demand function is introduced associated with Mussa - Rosen type of demand with vertically differentiated products (Mussas \& Rosen, 1978). Since we introduce Counot competition, we assume that middlemen are able to anticipate the effect of their choice on the price of both market sides of the food system. Based on the optimal profit problem of middlemen in market competition, we characterize the behavior of middlemen at market equilibrium in the case of both market sides. The result of trade quantities, the prices paid to the farmers and paid by consumers, and the profits of both farmers and middlemen at market equilibrium are pointed out to analyze the situation of the traditional food distribution in Vietnam. Based on this result, we propose policy implication for intervention market power of middlemen by creating a productivity shock in order to study the effect of land reform on the wealth of producers and consumers.

This paper contributes to the literature on the food distribution system for developing countries by studying the market power of middlemen in the food market. The works will bring a perspective for us to study the policy implication for controlling market imperfect competition and improving the wealth of both farmers and consumers.

\section{Overview of the Model}

Let us now move to the general assumption and notation of the model. We focus on three main characteristics as follow:

\subsection{Quantity and Prices}

We assume that middlemen buy food from farmers with the quantity denoted by $Q_{m}$, they pay farmers the food price $P_{f m}$. The quantity, which the middlemen sell at the final market low quality, denoted $Q_{\ell}$. We assume that, middlemen will sell all the quantity which he buys from farmers to the consumers market, which implies that the quantity at final market must be equal to the supply of the farmers or in other word, $Q_{\ell}=Q_{m}$. Middlemen sell foods to the consumers with the price $P_{\ell}$. Farmers obtain profit $\pi_{f m}$, and the wealth of middlemen remain when selling products to the market is denoted by $\pi_{m}$.

\subsection{Farmer and Food Production}

We introduce $\mathrm{N}$ farmers supplying foods for the middlemen. A farmer is characterized by production function. Since a farmer is symmetric and products are homogeneous, the production function of a farmer is characterized:

$$
q=f(\lambda)=\sqrt{ } \lambda
$$

With $\lambda$ is denoted for the labor used which transform in fruits and vegetables. In this production function, we set normalization rule with the wage $w=1$.

We now define the inverse supply function of farmers. Farmers play the game: with $P_{f m}$ is the price paid by the middle man, he will maximize their profit to the optimal level of labor used in the production. A farmer obviously solves $\max _{\lambda} P_{f m} f(\lambda)-\lambda$. The optimal level of labor is therefore given by $\lambda\left(P_{f m}\right)=\left(\frac{P_{f m}}{2}\right)^{2}$ and the individual vegetable supply is $f\left(\lambda\left(P_{f m}\right)\right)=\left(\frac{P_{f m}}{2}\right)$. Therefore, the total supply of vegetables $S_{m}\left(P_{f m}\right)$ for the middlemen is respectively given:

$$
S_{m}\left(P_{f m}\right)=N\left(\frac{P_{f m}}{2}\right)
$$


And the inverse supply functions is defined by:

$$
P_{f m}=\left(\frac{2 Q_{m}}{N}\right)
$$

\subsection{Middlemen, the Consumers and Demand for Low Quality Food}

We introduce $\mathrm{m}$ middlemen indexed $i$. They are symmetric and characterized by a linear cost function with simply is the transportation cost. The cost function therefore is defined as follow:

$$
C_{m}\left(q_{m, i}\right)=C_{m} \cdot q_{m, i}
$$

We define the willingness to pay by the low quality index which denoted is by $\ell$. Consumers at market low quality actually have two choices, they can buy low quality or do not buy the products. With the weight in the utility $\theta \in[0, \mathrm{~K}]$, if consumers buy low quality, the utility in this case is given by $U_{\ell}^{\theta}=\theta \cdot \ell-P_{\ell}$, and if consumers buy nothing $U_{\emptyset}=0$. From the utility function, of course we can consider that, the index low quality is larger than the cost of the middlemen in the natural way. Since $\mathrm{K}$ is the ranking of population who may enjoy buying in market low quality, we have naturally assumed that $\ell \mathrm{K}>C_{m}$. This assumption implies that the willingness to pay must be larger than the cost of the middlemen.

Let us now compute demand for low quality when we take prices with the property that $P_{\ell} \leq \ell \mathrm{K}$. Since the low quality good is increasing in $\theta$, we identify the agent $\underline{\theta}=\left(\frac{P_{\ell}}{\ell}\right)$ is indifferent between buying nothing or buying low quality. But this requires that $0 \leq \underline{\theta} \leq \mathrm{K}$. Since the consumers are uniformly distributed on $[0, K]$, the demands $D_{\ell}\left(p_{\ell}\right)$ for low quality food are respectively given by:

$$
D\left(p_{\ell}\right)=\left\{\begin{array}{c}
0 \text { if } P_{\ell}>\ell \mathrm{K} \\
{\left[K-\frac{P_{\ell}}{\ell}\right] \text { if } P_{\ell} \leq \ell \mathrm{K}}
\end{array}\right.
$$

Since we have in hand $D\left(p_{\ell}\right)$, we can verify the inverse demand function, the inverse demand correspondence P: $\left(Q_{\ell}\right) \in \mathrm{R}_{+}{ }^{2}$ therefore is given by

$$
P_{\ell}\left(Q_{\ell}\right)=\ell\left(\mathrm{K}-Q_{\ell}\right) \text { if } Q_{\ell} \geqq 0(\text { Note } 1)
$$

\section{Imperfect Competition in Both Market Sides}

\subsection{Definition}

Middlemen behavior will fully be described when middlemen have imperfect competition on both market sides of the food distribution system. In this case, middlemen not only choose the quantity buying from farmers but also anticipate consumers demand for the low quality. In fact, this means that they anticipate the effect of their choice on both prices. In the upstream, middleman anticipates supply quantity from farmers and given the price $p_{f m}$ to them which is given as $P_{f m}\left(\sum_{\substack{j=1 \\ j \neq i}}^{m} q_{i}^{*}+q_{i} N\right)$ at equilibrium. Similarly, in the downstream, he anticipates consumer demand and given the price $p_{\ell}\left(\sum_{\substack{j=1 \\ j \neq i}}^{m} q_{j}^{*}+q_{i}\right)$. This case we define as imperfect competition in both market sides of the food distribution system: the upstream with oliposony power and the downstream with oligopoly power. The definition at equilibrium of this case is given as:

Definition 1: At equilibrium of imperfect competition in the case of both upstream and downstream market power, $q_{i}^{*}, p_{\ell}^{*}, p_{f i n}^{*}$, is given as followi:

(i) Middlemen maximize their profit:

$$
\forall i, q_{i}^{*} \in \max _{q i}\left(p_{\ell}\left(\sum_{\substack{j=1 \\ j \neq i}}^{m} q_{j}^{*}+q_{i}\right)-p_{f m}\left(\sum_{\substack{j=1 \\ j \neq i}}^{m} q_{j}^{*}+q_{i}, N\right)-C_{m}\right) \cdot q_{i}
$$


(ii)

$$
P_{\ell}^{*}=P\left(\sum_{j=1}^{m} q_{j}^{*}\right) ; P_{f m}=P_{f m}\left(\sum_{j=1}^{m} q_{j}^{*}\right)
$$

\subsection{Price, Trade Quantity and Profit}

Since the maximization problem of middlemen has a price effect on both market sides of the food system, we consider $p_{f m}=2 \frac{q_{m}}{N}$ in the upstream, and $p_{\ell}\left(Q_{\ell}\right)=\ell\left(k-Q_{\ell}\right)$ in the downstream. The maximization is now given as:

$$
\forall i,\left(-\ell-\frac{2}{N}\right) \cdot q_{i}+\left(\ell\left(k-Q_{\ell}\right)-\frac{2 \sum_{i=1}^{m} q_{i}}{N}-c_{m}\right)=0
$$

By summing over $i$, this equation becomes:

$$
\left(-\frac{\ell}{m}-\frac{2}{m N}\right) q_{\ell}+\left(\ell\left(k-Q_{\ell}\right)-\frac{2 Q_{\ell}}{N}-c_{m}\right)=0
$$

This implies that the aggregate quantity is given by:

$$
Q_{\ell}=\frac{\ell k-c_{m}}{\left(\frac{\ell}{m}+\frac{2}{m N}+\frac{2}{N}+\ell\right)}
$$

From the difinition, we have at equilibrium: $\sum_{i=1}^{m} q_{j}^{*}=S\left(p_{f m}\right)$; We can therefore compute the price given to the farmer:

$$
\begin{aligned}
& \sum_{i=1}^{m} q_{j}^{*}=S\left(p_{f m}\right) \\
& \Leftrightarrow \frac{\ell k-c_{m}}{\left(\frac{\ell}{m}+\frac{2}{m N}+\frac{2}{N}+\ell\right)}=N \frac{P_{f m}}{2} \Rightarrow P_{f m}=\frac{2\left(\ell k-c_{m}\right)}{N\left(\frac{\ell}{m}+\frac{2}{m N}+\frac{2}{N}+\ell\right)}
\end{aligned}
$$

If we consider that, $\sum_{q=1}^{m} q_{i}=D(p)$ given by definetion, we can verify $P_{\ell}$ which is given as:

$$
p_{\ell}=\ell\left(k-Q_{\ell}\right)=\ell K-\ell\left(\frac{\ell k-c_{m}}{\left(\frac{\ell}{m}+\frac{2}{m N}+\frac{2}{N}+\ell\right)}\right)=\frac{\ell^{2} K N+\ell N m C_{m}+2 \ell K(1+m)}{(N \ell+2)(1+m)}
$$

Table 1. The result of the case of imperfect competition on both sides

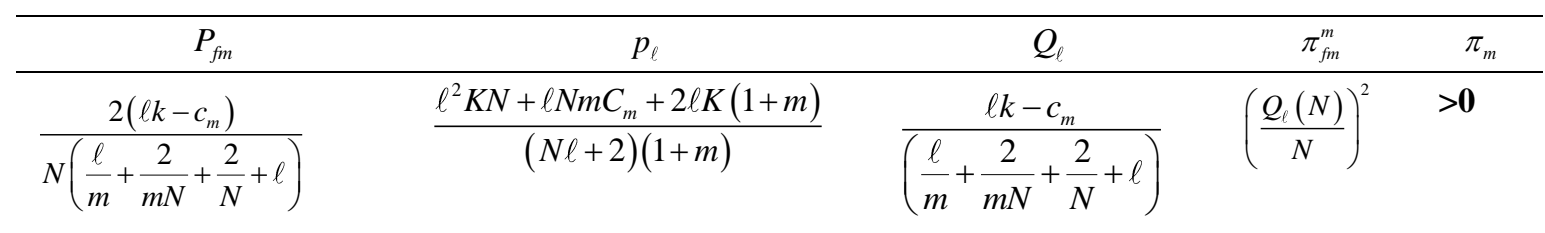

Source: Given by computation.

\subsection{Comparison and Discussion}

Perfect competition serves as a benchmark against which measure real - life and imperfectly competitive markets. To compare, let us now firstly study the market equilibrium of the case of perfect competition. If we keep the same way of computation as the previous case, we obtain the solution as follow:

Table 2. The result of the case perfect competition

\begin{tabular}{lccccc}
\hline Case & $P_{f m}$ & $P_{\ell}$ & $Q_{\ell}$ & $\pi_{\mathrm{f}}^{\mathrm{m}}$ & $\pi_{m}$ \\
\hline Perfect Competition & $\frac{2\left(\ell K-c_{m}\right)}{\ell N+2}$ & $\frac{\ell\left(2 K+N c_{m}\right)}{\ell N+2}$ & $\frac{\ell K-c_{m}}{\ell+\frac{2}{N}}$ & $\left(\frac{Q_{\ell}(N)}{N}\right)^{2}>0$ & Zero \\
& & & \\
\hline
\end{tabular}

Source: Given by all computation. 
If we consider that, in the case of pure competition, we obtain the result that the prices at which the intermediaries sell the products simply take into account the food price and operating cost: i.e. $P_{\ell}=P_{f m}+c_{m}$; This induces non credible out come, the profit of middlemen is zero which is a direct consequence of perfect competition. But this case obviously does not make sense in real - life of Viet Nam's food distribution. In fact, there are significant obstacles preventing perfect competition from appearing in food distribution markets. For instance, for the case of Vietnam, R.Wiersinga (2007) and Koen Maathuis (2006) show that: (i) Farmers are small and lack of market information, most farmers do not have a good view on potential market; (ii) Several same products are harvested at the same time with numerous quantities which need to be distributed quickly because of the weak necessary condition on storage; (iii) Fruits and vegetables are produced in different locations, at pre-urban areas, far from markets which consume big quantity; (iv) The infrastructure in bad condition causes high transportation cost. These situations imply that food market in perfect competition does not exist in Vietnam. In other words, on the food distribution system, the middlemen have market power in determining the price given to the farmers and consumers. From that point of view, we predict that, since middlemen have market power in both sides of the food system, the price paid to farmers is lower, and price given to consumers is higher comparing to market perfect competition.

Proposition 1: If we compare the case of imperfect competition on both sides with pure competition, we observe that:

(i) The price given to farmers is smaller, the price at the final consumer market is higher (i.e: $P_{f m}^{\text {Bothside }}<$ $P_{f m}^{\text {Perfect }}, P_{\ell}^{\text {Bothside }}>P_{\ell}^{\text {Perfect }}$ )

(ii) Trade quantity is smaller compare to all other perfect case (i.e: $Q_{\ell}^{\text {Bothside }}<Q_{\ell}^{\text {perfect }}$ )

(iii) Profit of middlemen positive in this case compared

(iv) to zero in perfect competition (i.e: $\pi^{m}>0$ )

(v) Profit of farmers lower since middlemen have both oligopsony and oligopoly power (i.e: $\pi_{f m}^{m \text { Bothside }}(N)<\pi_{f m}^{m \text { Perfect }}(N)$

The proposition 1 explains for the situation in Vietnam: To maximize their profits, middlemen use their market power on both market sides of the conventional food distribution system. This result also links to several studies related to behavior of middlem in food market in Vietnam. R.Wiersinga (2007) mentions that, to make sure all the quantities of vegetables buying from farmers have been sold at the final retail markets, in the downstream, middlemen firstly get information from retail market where they regularly sells vegetables. Based on his transportation cost and retail market information, they choose which market to go to; In the upstream, they go directly to the fields by themselves to collect the vegetables and give the money immediately to the farmers. This behavior obviously shows that, middlemen use their market power on both sides of market competition. Moreover, since middlemen have market power on both sides of the food system, they give lower price to the farmers and sell at high price in the final consumer markets. Koen Maathuis (2006) emphasizes that, the prices paid by middlemen to the farmers are very low. The main reasons why middlemen can only give very low price to the farmers are that: (i) Most of small farmers, especially poor farmers, need money immediately and they want to sell their products quickly instead of waiting for high price; (ii) Because of weak (or bad) facility conditions for storage and preservation, the quality of their products will be decreased rapidly; (iii) Farmers do not know about other potential buyers and information from retail markets. Even they buy with very low price from farmers; they sell at very high price at final market to gain excessive profit.

\section{Productivity Shock and the Effect of Land Reform}

\subsection{Productivity Shock}

Small land is a common feature of food production in many developing countries. For instance, in Vietnam, by the year 2016, in 9.29 households of agricultural production, there were up to 36.1 percent using land under 0.2 ha; only 2.3 percent cutivating on land over 0.5 ha (GSO, 2017). Such small land can be seen to have an impact on both benefit of food producers and consumers. The current situation of small land issues in Vietnam, and it impacts on the small food producers and communities in general are studied in several empirical works. Marsh et al. (2006) studied land policy in Vietnam focusing on the analysis of Vietnam's land policy through many periods and also the current situation. In a more specific case, Hung et al. (2007) examine the impact of land fragmentation in the north of Vietnam on crop productivity, labor use and other money expenses.

Since lands are small and fragmented, the aim of land reform is to make small land exploited and laborforce used 
more frequently and effectively for the expectation of reducing the production cost and improving productivity. This shock is therefore predicted to have an effect on the prices and the quantities of the food market. As a result, this policy can be an instrument to have an impact on the wealth of both producers and consumers. Based on such considerations, we directly introduce the parameter of land reform in the food production of the farmer. Since the intervention of this parameter is only on the supply markets equation, this means that nothing changes in the downstream of the food distribution system, what actually changes is only on supply market of the farmers. From that point of view, we obtain the sollution at market equilibrium in the case of imperfect competition in both market sides depending on the land reform parameter. Given from this intermediate result, we therefore can study the effect of land reform on the prices and quantities, at the same time, we can recognize how the wealth of farmers and consumers changed in this case of market competition. Based on such consideration, we directly introduce the parameter of land reform in the food production of the farmer as follow:

$$
q=f(\lambda)=\sqrt{\alpha \lambda}
$$

In which, $\lambda$ is labor used to produce vegetables. The optimal labor used of the famers in this context is given by: $\lambda=\left(\frac{\sqrt{\alpha} p_{f n}}{2}\right)^{2}$, the total supply of vegetables $Q_{m}(\alpha)$ for the middlemen are respectively given by: $Q_{m}(\alpha)=N \cdot \frac{\alpha p_{f n}}{2}$, and the inverse supply function is defined by $p_{f m}(\alpha)=\frac{2 Q_{m}}{\alpha N}$. Since nothing is changed in the demand at the downstream of the food system, we observe that what is only changed in the equation of maximization problem of middlemen is that $\alpha$ multiplies by $\mathrm{N}$. By using the same computation as in item 4.2, we obtain the prices and quatities at market equilibrium in the case of imperfect competition in both sides.

Proposition 2: The final solution of market equilibrium in the case of both sides is given by:

\begin{tabular}{cccc}
\hline Case & $p_{f n}(\alpha)$ & $p_{\ell}(\alpha)$ & $Q_{\ell}(\alpha)$ \\
\hline Both sides & $\frac{2\left(\ell K-c_{m}\right)}{\left(1+\frac{1}{m}\right)(\alpha N \ell+2)}$ & $\frac{\alpha\left(\ell^{2} K N+\ell N m c_{m}\right)+2 \ell K(1+m)}{(\alpha \ell N+2)(1+m)}$ & $\frac{\ell K-c_{m}}{\left(1+\frac{1}{m}\right)\left(\ell+\frac{2}{\alpha N}\right)}$ \\
\hline
\end{tabular}

\subsection{The Effect of Land Reform}

To observe the effect of land reform on the prices and the quantities, we compute the elasticity which reflects the reaction of the prices to the changes of $\alpha$. This elasticity $E p_{f m}$ in fact is computed by $E p_{f m}=\frac{d p_{f m}(\alpha)}{d \alpha} \cdot \frac{\alpha}{p_{f m}(\alpha)}$ and $E p_{\ell}=\frac{d p_{\ell}(\alpha)}{d(\alpha)} \cdot \frac{\alpha}{p_{\ell}(\alpha)}$.

Proposition 3: Given by our computation, the effect of land reform on prices and quantities is given as follow:

\begin{tabular}{lccc}
\hline Case & Elasticity of $P_{f m}$ & Elasticity of $P_{\ell}$ & Quantity \\
\hline Both sides & $-\left(\frac{\alpha \ell N}{\alpha \ell N+2}\right)<0$ & $-\frac{2 \alpha(1+m)\left(\ell K-c_{m}\right)}{\left(\alpha \ell N\left(\ell K+c_{m}\right)+2 \ell K(1+m)\right)(\alpha \ell N+2)(1+m)}$ & $\frac{d Q_{\ell}}{d(\alpha)}>0$ \\
\hline
\end{tabular}

The result at proposition 3 show that the consumers buy food at the cheaper price $\left(E p_{\ell}<0\right)$ on final demand market while farmers receive lower price paid from middlemen $\left(E p_{f m}<0\right)$ on the food market supply of the farmers. This result implies that land reform benefits to the consumer but have negative effect on farmers. However, this situation can be improved by the fact that farmers can sell more products by improving productivity $\left(\frac{d Q_{l}^{\alpha}}{d a}>0\right)$ and lower production cost by using land more flexible. Our results make sense with the empirical studies of Nguyen (2008, 2012), which state that land reform in Viet Nam has positive effects on crop productivity of households and increase food production. These results obviously appear in our model since land 
reform improves productivity and benefit to both farmers and consumers by selling more foods and buying at cheaper price.

\section{Conclusion and Limitation}

This work proposes an industrial organization model of middlemen market power in the traditional food distribution system. We show that, since middlemen have market power, there is always a distortion with respect to perfect competition in the price paid to farmers and sold to the consumers. Our model explains the phenomenon in the food market of Vietnam, that is, middlemen use their market power to gain excessive profit from farmers and the consumers. In the context of Vietnam, the price of fruits and vegetables fluctuates and the intermediaries always exercise a pressure on the price paid to the farmers while they sell at very high prices at consumer market (Wiersinga, 2007; Koen Maathuis, 2006; Moustier et al., 2007, 2010). We establish the land reform policy, which is expected to improve productivity and increased the wealth of both farmers and consumers by making small land exploited and labor force used more flexible and effective; the result indicates effects of land reform on the wealth of farmers and consumers. The limitation of this model can be studied in further research; which would address the question the best choice of land reform in the food system.

\section{Acknowledgments}

I am grateful to my thesis advisor, Prof. Hubert STAHN, Aix Marseille University (Aix Marseille School of Economics, AMSE - GREQAM), France, for his guidance and advice; I would like to thank participants in Phd seminar (GREQAM) for their valuable comments and interesting questions.

\section{References}

Cadilhol, J. J., Moustier, P., Poole, N. P., Tam, P. T. G., \& Fearne, A. P. (2006). Traditional vs. Modern Food System? Insights from Vegetable Supply Chains to Ho Chi Minh city (Viet Nam). Development Policy Review, 24(1), 31-49. https://doi.org/10.1111/j.1467-7679.2006.00312.x

Chau, N. H., Goto, H., \& Kanbur, R. (2009). Middlemen, Non-Profits, and Poverty. CEPR Discustion papers No.7459.

Genenal Statistic Office of Vietnam. (2017a). Statistical Year Book of Viet Nam 2016. Statistical Publishing House. Retrieved from https://www.gso.gov.vn/default.aspx?tabid=512\&idmid=5\&ItemID=18531

Genenal Statistic Office of Vietnam. (2017b). The Rural, Agricultural and Fishery Census 2016. Retrieved from https://www.gso.gov.vn/default.aspx?tabid=512\&idmid=5\&ItemID=18595

Hung, P. V. et al. (2007). The Economics of Land Fragmentation in the North of Vietnam. Australian Journal of Agricultural and Resource Economics, 51, 195-211. https://doi.org/10.1111/j.1467-8489.2007.00378.x

Koen, M. (2006). Market Access for Small Family Farmers in 2015. Final Report on Preparation Study. Retrieved from https://betuco.be/marketing/Marketing\%20Veco\%20vietnam.pdf

Marsh, S. P., MacAulay, T. G., \& Hung, P. V. (Eds). (2006), Agricultural Development and Land Policy in Viet Nam. Australia Centre for International Agricultural Reseach-ACIAR Monograph, (124), 272.

Maruyama, M., \& Trung, L. V. (2007). Supermarket in Viet Nam: Opportunies and Obstacles. Asian Economic Journal, 2l(1), 19-46. https://doi.org/10.1111/j.1467-8381.2007.00245.x

Maruyama, M., \& Trung, L. V. (2010). The Nature of Informal Food Bazaars: Empirical Results for Urban Hanoi, Vietnam. Journal of Retailing and Consumer Services, 17(1), 1-9. https://doi.org/10.1016/j.jretconser.2009.08.006

Maruyama, M., \& Trung, L. V. (2012). Modern Retailers in Transition Economies: The case of Viet Nam. Journal of Macro Marketing, 32(1), 31-51. https://doi.org/10.1177/0276146711421932

McCorriston, S. (2002). Why Should Imperfect Competition Matter to Agricultural Economists? European Review of Agricultural Economics, 29(3), 349-371. https://doi.org/10.1093/eurrag/29.3.349

Merel, P. R., Sexton, R. J., \& Suzuky, A. (2009). Optimal Investment in Transport Infrastructure When Middlemen Have Market Power: A Developing Countries Analysis. American Journal of Agricultural Economics, 91(2), 462-76. https://doi.org/10.1111/j.1467-8276.2008.01245.x

Moustier, P. (2007). Final Summary Report of Susper (Sustainable Development of Peri-urban Agriculture in South-East Asia). Hanoi: The Gioi Publishers.

Moustier, P., Phan, T. G. T., Dao, T. A., Vu, T. B., \& Nguyen, T. T. L. (2010). The Role of Farmer Organizations 
in Supplying Supermarkets with Quality Food in Viet Nam. Food Policy, 35, 69-78. https://doi.org/10.1016/j.foodpol.2009.08.003

Mussa, M., \& Rosen, S. (1978). Monopoly and Product Quality. Journal of Economic Theory, 18, 301-317. https://doi.org/10.1016/0022-0531(78)90085-6

Myers, J. R., Sexton, R. J., \& Tomek, W. G. (2010). A Century of Research on Agricultural Markets. American Journal of Agricultural Economics, 92(2), 376-402. https://doi.org/10.1093/ajae/aaq014

Ngo, C. T. (2017). Middlemen Behavior in Vietnam's Traditional Food Distribution System: The Case of Upstream Market Power. International Journal of Applied Business and Economic Research, 15(23).

Nguyen, T. T. (2008). The Impact of Land Reform on Farm Households in the Northern Uplands of Vietnam. Farming \& Rural Systems Economics Series, 97, 213. Weikersheim: Margraf Publishers.

Nguyen, T. T. (2012). Land Reform and Farm Production in the Northern Uplands of Vietnam. Asian Economic Journal, 26(1), 43-61. https://doi.org/10.1111/j.1467-8381.2011.02067.x

Rogers, R. T., \& Richard, J. S. (1994). Assessing the Importance of Oligopsony Power in Agricultural Markets. American Journal of Agricultural Economics, 76(5), 1143-150. https://doi.org/10.2307/1243407

Sexton, R. J., \& Nathalie, L. (2001). Food Processing and Distribution: An Approach Industrial Organization. In B.Garner, \& G. Rausser (Eds.), Handbook of Agricultural Economics (Vol. 1). Elsevier Science B.V.

Van Wijk, M. S., Trahuu, C., Tru, N. A., Gia, B. T., \& Hoi, P. V. (2006). The Traditional Vegetable Retail Marketing System of Ha Noi and the Possible Impacts of Supermarkets. Acta Horticulturae, 699, 465-475. https://doi.org/10.17660/ActaHortic.2006.699.55

Wiersinga, R. C., Van Wijk, M. S., \& Luyen, C. H. (2007). Marketing channel choice and marketing timing of prei - urban vegetable growers in Vietnam. Acta Hortic. 762, 373-380. https://doi.org/10.17660/ActaHortic.2007.762.36

\section{Note}

Note 1. Readers can refer at Ngo Chi Thanh (2017) for this inverse function and the case of upstream market power.

\section{Appendix A}

\section{Proof of the case of pure competition}

The definition of this case at equilibrium is given by:

Definition: At equilibrium, $\left(\lambda_{j}^{*}\right)_{j=1}^{N},\left(q_{i}^{*}\right)_{i=1}^{m}, p_{f m}^{*}, p_{\ell}^{*}$, are defined as follow:

$$
\text { Middle man maximize profit: } \forall i, q_{i}^{*} \in \max _{q_{i}}\left(P_{\ell}-P_{f m}-C_{m}\right) \cdot q_{i}
$$

(ii) Farmer maximize supply quality: $\forall j \lambda^{*} \in \operatorname{argmax}_{\lambda} p_{f m} f\left(\lambda_{\mathrm{j}}\right)-\lambda_{\mathrm{j}}$

(iii) $\quad \sum_{i=1}^{m} q_{j}^{*}=f\left(\lambda_{j}^{*}\right)=D(p)$

Based on the method of Lagrange multiplier subject to constrain, the Karush--Kuhn--Tucker conditions is used for equality constrains, the condition for maximization of each middle man therefore given as follow

$$
\left\{\begin{array}{c}
P_{\ell}-P_{f m}-C_{m}+\beta=0 \\
\beta . q=0, q>0
\end{array}\right.
$$

To satisfy the first order condition in (1), we obviously have two cases: (i) When $\beta>0$ then $q=0$; and $\beta=$ $-P_{\ell}+P_{f m}+C_{m}>0$; (ii) When $\beta=0$ then $\mathrm{q}>0$ and $P_{\ell}=P_{f m}+C_{m}$. We can therefore summary the situation of these two cases as follow:

$$
S\left(P_{\ell}, P_{f m}\right)=\left\{\begin{array}{c}
0 \text { if } P_{\ell} \leq P_{f m}+C_{m} \\
{[0,+\infty], \text { if } P_{\ell}=P_{f m}+C_{m}} \\
+\infty, \text { if } P_{\ell} \geqq P_{f m}+C_{m}
\end{array}\right.
$$

When $\lambda=0$ and the trade quantity are positive, at equilibrium, the price in the downstream of the food system is given by:

$$
p_{\ell}=p_{f m}+c_{m}
$$

We replace $P_{\ell}$ in (2) to the inverse demand $P_{\ell}\left(Q_{\ell}\right)=\ell\left(\mathrm{K}-Q_{\ell}\right)$ if $Q_{\ell} \geqq 0$, the trade quantity is given: 


$$
Q_{\ell}=K-\left(\frac{P_{f m}+c_{m}}{\ell}\right)
$$

If we have in mind that the aggregate quantity supply at equilibrium of the farmers $Q_{\mathrm{m}}$ given by $S_{m}\left(P_{f m}\right)=$ $N\left(\frac{P_{f m}}{2}\right)$. We also have: $Q_{\ell}=Q_{\mathrm{m}}$. Therefore:

$$
k-\left(\frac{p_{f n}+c_{m}}{\ell}\right)=N\left(\frac{p_{f n}}{2}\right)
$$

The price which farmers receive from middlemen is given as:

$$
P_{f m}=\frac{2\left(\ell K-c_{m}\right)}{\ell N+2}
$$

Since the price paid to the farmers $P_{f m}$, we replace $P_{f m}=\frac{2\left(\ell K-c_{m}\right)}{\ell N+2}$ to (2) to compute $P_{\ell}$, the price at market low quality in perfect competition is given by:

$$
P_{\ell}=\left(\frac{2 \ell K+\ell N c_{m}}{\ell N+2}\right)=\frac{\ell\left(2 K+N c_{m}\right)}{\ell N+2}
$$

We can now move to verify the aggregate quantity in the downstream market. This quantity is computed by replacing $P_{f m}=\frac{2\left(\ell K-c_{m}\right)}{\ell N+2}$ to $Q_{\ell}$ at (3) We therefore obtain that:

$$
Q_{\ell}=\frac{\ell K-c_{m}}{\ell+\frac{2}{N}}
$$

Since we consider the assumption: $\ell K>c_{m}$, we observe that $Q_{\ell}=\frac{\ell K-c_{m}}{\ell+\frac{2}{N}}$ is positive.

Let us recall the production of the farmer: $q=f(\lambda)=\sqrt{ } \lambda$, given by the definition at equilibrium, a farmer maximizes his labor used, he solves $\max _{\lambda} P_{f m} f(\lambda)-\lambda$. If we consider that total number of farmers serve for middlemen are $\mathrm{N}$, we know that they operate competitively, and choose the amount of labor that they dedicate to their activity. Under our assumptions their indirect profit is given by $\pi_{f}^{m}(p)=\frac{1}{4}\left(P_{f m}\right)^{2}$. If we now have in mind that the inverse supply of vegetable is given by $P_{f m}=2 \frac{Q_{\ell}}{N}$ (and $Q_{\mathrm{m}}=Q_{\ell}$ by definition at equilibrium). We can say that the wealth of this farmer are given by:

$$
\pi_{f}^{m}(N)=\left(\frac{\left(\ell K-c_{m}\right)}{\ell N+2}\right)^{2}
$$

Since $\ell \mathrm{K}>c_{m}$, we can go to conclude that in perfect competition, at equilibrium, the wealth of farmers is positive. The farmers not only receive the price from middlemen but also take all the cost from them.

On the other hand, at equilibrium, the price at final market equal to price the middlemen paid for farmers plus the cost:

$$
P_{\ell}=P_{f m}+c_{m}
$$

This means that the profit which middlemen remaining is equal to zero.

\section{Proof of proposition 1}

If we have considered Table 1 and Table 2, we can now compare to the prices, trades, and profits.

(1) Compare $P_{f m}$

$$
p_{f i n}^{\text {Bothside }}-p_{f i n}^{\text {perfect }}=-\left(\frac{2}{N \ell+2}\right)\left(\frac{\ell k-c_{m}}{m+1}\right)<0 \Rightarrow p_{f i n}^{\text {Bothside }}<p_{f i n}^{\text {perfect }}
$$

(2) Compare $p_{\ell}$

$$
p_{\ell}^{\text {Bothside }}-p_{\ell}^{\text {perfect }}=\left(\frac{N \ell}{N \ell+2}\right)\left(\frac{\ell k-c_{m}}{m+1}\right)>0 \Rightarrow p_{\ell}^{\text {Bothside }}>p_{\ell}^{\text {perfect }}
$$


(3) Compare $Q_{\ell}$

$$
Q_{\ell}^{\text {Bothside }}-Q_{\ell}^{\text {perfect }}=-\left(\frac{N}{N \ell+2}\right)\left(\frac{\ell k-c_{m}}{m+1}\right)<0 \Rightarrow Q_{\ell}^{\text {Bothside }}<Q_{\ell}^{\text {perfect }}
$$

(4) Compare $\pi_{f m}^{m}$

Since we have in hand that $Q_{\ell}^{\text {Bothside }}<Q_{\ell}^{\text {perfect }}$, we can therefore conclude that $\pi_{f m}^{m B o t h s i d e}(N)<\pi_{f m}^{m \text { Perfect }}(N)$ since we consider that $\pi_{f m}^{m}=\left(\frac{Q_{\ell}(N)}{N}\right)^{2}$

(5) Compare $\pi_{m}$

$$
\pi^{m \text { Bothside }}=\left(p_{\ell}^{\text {Bothside }}-p_{f m}^{\text {Bothside }}-c_{m}\right) Q_{\ell}^{\text {Bothside }}=\left(\frac{N m}{N \ell+2}\right)\left(\frac{(\ell k-c m)^{2}}{(m+1)^{2}}\right)>0
$$

\section{Proof of proposition 3}

(1) Elasticity of $p_{f m}$

Given by $E p_{f m}=\frac{d p_{f m}}{d \alpha} \cdot \frac{\alpha}{p_{f m}(\alpha)}$, since $p_{f m}^{\text {Bothsides }}(\alpha)=-\frac{2\left(\ell K-c_{m}\right)}{\alpha N\left(1+\frac{1}{m}\right)\left(\ell+\frac{2}{\alpha N}\right)}$, we have:

$$
\frac{d p_{f m}}{d(\alpha)}=-p_{f m}\left(\frac{\ell N\left(1+\frac{1}{m}\right)}{(\alpha \ell N+2)\left(1+\frac{1}{m}\right)}\right) \Rightarrow E_{p_{f m}}^{\text {Bothsides }}=-\frac{\alpha \ell N}{(\alpha \ell N+2)}<0
$$

(2) Elasticity of $p_{\ell}$

We have $p_{\ell}(\alpha)=\frac{\alpha\left(\ell^{2} K N+\ell N m c_{m}\right)+2 \ell K(1+m)}{(\alpha \ell N+2)(1+m)}$; to simpify, let us set:

$$
\begin{aligned}
E=\alpha \ell N\left(\ell K+m c_{m}\right)+2 \ell & K(1+m) ; F=(\alpha \ell N+2)(1+m) \\
& \frac{d p_{\ell}}{d \alpha}=\frac{\ell N\left(\ell K+m c_{m}\right) \cdot F-\ell N(1+m) \cdot E}{F^{2}} \\
& \Rightarrow E p_{\ell}=\frac{d p_{\ell}}{d \alpha} \cdot \frac{\alpha}{p_{\ell}}=\left(\left(\frac{\ell N\left(\ell K+m c_{m}\right) \cdot F-\ell N(1+m) E}{F^{2}}\right) \cdot \frac{F}{E}\right) \cdot \alpha \\
& =\left(\frac{\ell N\left(\ell N+m c_{m}\right)}{E}-\frac{\ell N(1+m)}{F}\right) \cdot \alpha \\
& =-\frac{2 \alpha(1+m) m \ell N\left(\ell K-c_{m}\right)}{\left(\alpha \ell N\left(\ell K+m c_{m}\right)+2 \ell K(1+m)\right)((\alpha \ell N+2)(1+m))}<0
\end{aligned}
$$

(3) The effect of quantity

In fact, we have to proof that $\frac{d Q_{\ell}}{d \alpha}>0$, if we have considered the solution of quantity at market equilibrium at proposition 2, which is: $Q_{\ell}(\alpha)=\frac{\ell K-c_{m}}{\left(1+\frac{1}{m}\right)\left(\ell+\frac{2}{\alpha N}\right)}$, we can easily obtain that, $\frac{d Q_{\ell}}{d \alpha}=\frac{2 Q_{\ell}}{\alpha(\alpha \ell+2)}>0$

\section{Copyrights}

Copyright for this article is retained by the author(s), with first publication rights granted to the journal.

This is an open-access article distributed under the terms and conditions of the Creative Commons Attribution license (http://creativecommons.org/licenses/by/4.0/). 